IN PRACTICE

\title{
Screening injecting drug users for sexually transmitted infections and blood borne viruses using street outreach and self collected sampling
}

\author{
C S Bradshaw, LI Pierce, S N Tabrizi, C K Fairley, S M Garland
}

Sex Transm Infect 2005;81:53-58. doi: 10.1136/sti.2004.009423

See end of article for authors' affiliations

Correspondence to:

C Bradshaw, Melbourne

Sexual Health Centre, 580

Swanston Street, Carlton,

3053, Victoria, Australia;

cbradshaw@mshc.org.au

Accepted for publication 18 March 2004
Background: Injecting drug users (IDUs) are a marginalised population, who infrequently access health services for screening for sexually transmitted infections (STIs) and blood borne viruses (BBVs), and are at high risk of these infections.

Objectives: To use street outreach and self collection of samples for STI screening, to establish the prevalence of BBVs and STls, and to identify risk behaviours among a group of culturally diverse street based IDUs.

Methods: This was a cross sectional study of 314 IDUs in the central business district of Melbourne, Australia, conducted over 3 years (1999-2002). We used street outreach as the recruitment strategy with staff "on foot" in injecting and dealing locations, as well as self collected genital sampling to increase acceptance of screening for Neisseria gonorrhoeae, Chlamydia trachomatis, and Trichomonas vaginalis by polymerase chain reaction (PCR). Individuals were screened for hepatitis A, B, and C, syphilis and HIV, and given the option of a self collected or clinician collected blood sample to increase acceptance of screening for BBVs.

Results: Street outreach was highly effective and self directed STI sampling was more acceptable than practitioner directed sampling $(76 \%$ versus $9 \%$ acceptance, $p<0.001)$. There was a high prevalence of hepatitis C (74\%, 95\% Cl 69 to 79), STIs ( $8 \%$ (5 to 13)), and chlamydia (6\% (3 to 10)), and past exposure to hepatitis $A$ and $B$ was common. High rates of recent sharing of injecting equipment, unprotected sex and casual sexual partners, together with low levels of awareness of current hepatitis $C$ infection were identified.

Conclusion: Street outreach and self collected genital samples facilitate screening for STIs and BBVs in IDUs and revealed a high prevalence of infections and risk behaviours.

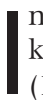
jecting drug users (IDUs) are a marginalised population known to have a high prevalence of blood borne viruses (BBVs) and sexually transmitted infections (STIs) through unsafe injecting and sexual risk behaviours. ${ }^{1-4}$ Hepatitis $C$ (HCV) is highly prevalent in IDUs worldwide (50-95\%). ${ }^{5-10}$ In Australia HCV prevalence has been reported to be $50-70 \%$, and at least $80 \%$ of $\mathrm{HCV}$ infections are related to injecting drug use. ${ }^{11}$ Despite hepatitis B (HBV) and A (HAV), being vaccine preventable diseases, they exist at moderate prevalence in IDUs. ${ }^{12}{ }^{13}$ In contrast with North America and eastern Europe, where an HIV prevalence of 5-56\% in IDUs has been reported, ${ }^{314} 15$ the HIV prevalence in Australian IDUs is significantly lower at $1-2 \% .^{12}{ }^{16}$

Injecting drug use is associated with unsafe sexual practices and a high prevalence of STIs. ${ }^{1-3}$ Factors contributing to a high risk of STIs include exchange of sex for drugs, high rates of commercial sex work, high lifetime number of sexual partners and partner change, and high lifetime prevalence of STIs. ${ }^{1-4}$ It has been suggested that drug use may make IDUs less aware or concerned about STIs, may increase the threshold for attending health services, and that standard STI control programmes do not generally reach IDUs. ${ }^{4}$ Conventional screening practices, which involve invasive genital tract examination, can create a further barrier to STI testing. Self collected sampling, with detection of STIs by polymerase chain reaction (PCR), has been found to be more acceptable among groups with low rates of practitioner directed screening, ${ }^{17}{ }^{18}$ and are ideally suited to improve STI screening rates in IDUs.
Providing IDUs with testing and treatment for STIs and BBVs is an important part of harm reduction programmes, and will improve the health of these individuals and their communities. However, providing appropriate services to IDUs is challenging. Those most at risk and from culturally and linguistically diverse backgrounds may be less likely to attend current health services. Street outreach is recognised as an important component of needle syringe exchange programmes to access those at highest risk. ${ }^{19}$ Employing street outreach is likely to facilitate STI and BBV screening in IDUs.

In this study we used street outreach and self collection of samples for STI screening to establish the prevalence of BBVs and STIs, and to identify risk behaviours, among a group of culturally diverse street based IDUs.

\section{METHODS}

A cross sectional study was conducted over 3 years (19992002), among IDUs attending a weekly outreach service of Melbourne Sexual Health Centre (MSHC), which aimed to service street based IDUs in the central business district (CBD) of Melbourne, Australia. Staff approached IDUs in known injecting locations "on foot." Individuals who had not recently been screened for BBVs and STIs were counselled in the street and encouraged to accompany staff back to the clinic. A record of the number of IDUs approached on the

Abbreviations: BBVs, blood borne viruses; IDUs, injecting drug users; PCR, polymerase chain reaction; STIs, sexually transmitted infections 
street who declined to attend the service was not kept. A mobile needle exchange operating "on foot" in the CBD also referred clients in need of medical attention and assisted in recruitment.

The clinic was located close to the main injecting areas in the CBD. It was open into the evening and had an informal appearance, with a lounge where non-medical needs such as accommodation could be discussed. After obtaining informed consent, staff administered a standard questionnaire on injecting and sexual practices. Participants had a blood sample drawn, and were supervised in taking their own sample if they preferred this option (data on the number who preferred this method were not collected). The first 56 participants were enrolled in a pilot study, the purpose of which was to establish the appropriateness of the location, whether the service was attended, and uptake of STI screening. Self collection of samples for STI screening was introduced after the pilot study, as acceptance of standard STI screening practices was low. The participants in the pilot study and subsequent study were selected from IDUs who were injecting and dealing in the same geographical location, in the CBD of Melbourne. The service was free, and vaccination for $\mathrm{HAV}$ and $\mathrm{HBV}$ was offered to individuals found to be non-immune.

Serology for HCV, HBV, HAV, HIV, and syphilis was performed by the Victorian Infectious Diseases Reference Laboratory (VIDRL) using HCV EIA 3.0 and Murex anti-HCV version 4.0 (Abbott Diagnostics, IL, USA); HBV core antigen recombinant corzyme diagnostic kit, IMX HbsAg (V2) kit and IMX AUSAB kit (Abbott); IMX HAVAB (Abbott); HIVl/2 gO Enzyme Immuno-assay Kit (Abbott) and the HIV Blot 2.2 western blot assay (Diagnostic Technology, Miami, FL, USA); and the Macro-Vue RPR card test (Becton Dickinson, NJ, USA) and Treponstika TP recombinant EIA (BioMerieux, Marcy l'Etoile, France).

A genital sample was collected from consenting individuals. In the initial pilot study $(\mathrm{n}=56)$, STI screening was offered with genital examination and practitioner collected samples. Endocervical and vaginal specimens were collected for Neisseria gonorrhoeae (NG), Chlamydia trachomatis (CT), and Trichomonas vaginalis (TV) from women, and urethral specimens were collected for CT and NG from men. Individuals who declined examination and practitioner screening were offered self collected urine sampling to be tested for CT only. CT testing was performed using the Chlamydia Amplification Assay Abbott LCx probe system (Abbott Diagnostics, IL, USA). Specimens for NG and TV testing were inoculated directly into Gonococcus and Trichomonas medium for culture. Gonococcal plates were placed into a candle extinction jar and specimens were transported to MSHC's laboratory within 4 hours.

Self collected sampling was introduced after the pilot study as the sole method of screening. Participants were given careful instructions on self collection of samples, which they then performed in the adjacent toilet. Women self inserted tampons into the vagina and then placed them in transport medium. Men, and any women who declined the tampon method, provided a first pass urine sample. If they were unable to void, or had just voided, they were asked to return in an hour. Individuals who had symptoms or underwent cervical cytology screening were examined after the self collected sample had been obtained. All specimens were stored at $4^{\circ} \mathrm{C}$ overnight and transported to the Molecular Microbiology Laboratory of the Royal Women's Hospital, Melbourne, Australia. PCR was performed to detect CT, NG, and TV. Three amplification reactions were performed on extracted DNA from each tampon or urine specimen ${ }^{20}$ : (i) combined amplification of CT and NG sequences using Roche COBAS Amplicor (Roche Diagnostics, Branchburg, NJ, USA); (ii) amplification of TV sequences ${ }^{21}$; and (iii) amplification of $\beta$ globin gene sequences as positive internal control. ${ }^{22}$ All positive NG specimens were confirmed using real time PCR assay directed to cppB gene. ${ }^{23}$ Strict procedures avoiding specimen contamination and carryover were followed.

All participants diagnosed with an STI were notified, and medication was provided free of charge. CT was treated with $1 \mathrm{~g}$ of oral azithromycin, TV with $2 \mathrm{~g}$ of oral tinidazole, and NG with $250 \mathrm{mg}$ of intramuscular ceftriaxone. Sexual contacts were traced and treated where possible.

The research and ethics committees of the Royal Women's Hospital, Victoria, approved this study. Data were entered and managed in Microsoft Access. Proportions were compared using $\chi^{2}$ and Fisher's exact tests where appropriate, and $95 \%$ confidence intervals were calculated for all prevalences. Logistic regression was used for multivariate analysis and ANOVA was performed using SPSS for Windows Version 11, Chicago, IL, USA. Patients were excluded from the analysis where clinical information or specimens were not available.

\section{RESULTS}

In all, 314 IDUs attended the outreach service, and agreed to answer the questionnaire and to be screened for BBVs. There was no record kept of the number who were told about the programme but did not attend, as recruitment was informal and IDUs were often in groups when approached. Table 1 shows the characteristics of the study group. The median age was 24 years old, $63 \%$ were male, $11 \%$ identified as Indigenous Australian, and $7 \%$ as South East Asian. The participants in the pilot study were included in the overall analysis of the 314 participants, except in the analysis of acceptance of STI screening and STI prevalence. Participants

Table 1 Demographics and social parameters of study population

\begin{tabular}{ll}
\hline Total number of participants & 314 \\
\hline Median age & 24.2 years (17-45 years) \\
Sex & $197(63 \%)$ \\
Male & $116(37 \%)$ \\
Female & 1 \\
Transgender & $290(94 \%)$ \\
Sexual preference & $12(4 \%)$ \\
Heterosexual & $7(2 \%)$ \\
Homosexual & 5 \\
Bisexual & $223(71 \%)$ \\
Unknown & $34(11 \%)$ \\
Cultural background & $22(7 \%)$ \\
Anglo-Australian & $35(11 \%)$ \\
Indigenous Australian & $272(88 \%)$ \\
Southeast Asian & $38(12 \%)$ \\
Other & 4 \\
Current employment status & $135(44 \%)$ \\
Unemployed & $171(56 \%)$ \\
Partial/full employment & 8 \\
Unknown &
\end{tabular}


Table 2 Prevalence of STls and acceptance of screening by method offered

\begin{tabular}{|c|c|c|c|c|c|}
\hline Screening method & $\begin{array}{l}\text { Acceptance of CT } \\
\text { screening }\end{array}$ & $\begin{array}{l}\text { Acceptance of NG and TV } \\
\text { screening }\end{array}$ & $\mathrm{CT}$ prevalence & TV prevalence & NG prevalence \\
\hline $\begin{array}{l}\text { Practitioner collected samples } \\
\text { Self collected samples }\end{array}$ & $\begin{array}{l}18 / 56(32 \%)^{*} \\
195 / 258(76 \%)\end{array}$ & $\begin{array}{l}5 / 56(9 \%) \\
195 / 258(76 \%)\end{array}$ & $\begin{array}{l}0 / 18 \\
12 / 195(6 \%)\end{array}$ & $\begin{array}{l}0 / 5 \\
3 / 195(2 \%)\end{array}$ & $\begin{array}{l}0 / 5 \\
1 / 195(1 \%)\end{array}$ \\
\hline
\end{tabular}

CT, Chlamydia trachomatis; NG, Neisseria gonorrhoeae; TV, Trichomonas vaginalis.

*This group included individuals who declined genital examination but then agreed to self collection of urine for CT screening only.

in the pilot study did not differ significantly from IDUs in the subsequent study in terms of sex, age, cultural background, and sexual and injecting practices.

\section{Prevalence of STIs and method of sampling}

Acceptance of genital examination and practitioner collected sampling in the pilot study $(\mathrm{n}=56)$ was low $(9 \%(95 \%$ CI 3 to 19); table 2). It was recognised that if these individuals were then offered self screening for CT only by urine collection, substantially more accepted testing (32\% (95\% CI 21 to 45 ); $\mathrm{p}<0.01$ ). As genital examination appeared to be a barrier to the acceptance of screening in the pilot study, self collected sampling was subsequently introduced as the sole method of screening in the study. STI screening by self collected sampling had a substantially greater level of acceptance among participants (76\% $(95 \%$ CI 70 to 81$) ; p<0.001$ compared to practitioner sampling). IDUs who did not participate in STI screening by self sampling were more likely to be male $(75 \%$ versus $56 \%, \mathrm{p}<0.01)$, less likely to have casual sexual partners (47\% versus $77 \%, \mathrm{p}<0.05)$, and less likely to engage in sex work ( $3 \%$ versus $17 \%, p<0.01$ ). There were no other statistically significant differences between the groups, particularly with regard to unprotected sexual practices, sexual preference, cultural background, and age. Reasons given for declining screening included having "been tested" and being "in a hurry," and some men reported being unable to void after recent heroin use. No women reported difficulty with tampon insertion or stated this was a reason for declining screening.

The overall prevalence of STIs in those who consented to screening for CT, NG, and TV was $8 \%$ (95\% CI 5 to 13). All STIs detected were from self collected samples. The prevalence of CT was moderate $(6 \%, 95 \%$ CI 3 to 10$)$ with the majority Anglo-Australian (92\%) and female (67\%). There was a low prevalence of TV $(2 \%, 95 \%$ CI 0.3 to 4$)$; all were female, with one additional equivocal result in a male contact of TV (low copy numbers). Only one case GC (1\%, 95\% CI 0.01 to 3) was found, in an Anglo-Australian female. All cases and traceable sexual contacts were notified and treated. There were two cases of past treated syphilis in Indigenous Australian females and no cases of untreated syphilis.

\section{Risk behaviours for STIs}

The majority of individuals identified as heterosexual (94\%), with 6\% either homosexual or bisexual. Casual sexual partners were common; $48 \%$ (95\% CI 42 to 54) reported having one or more casual sexual partners (CSP) over the previous 6 months (table 3 ). There was a high prevalence of unprotected sex; $65 \%$ (95\% CI 59 to 71 ) stated they had not used condoms for vaginal or anal sex in the last 6 months. The highest prevalence of unprotected sex was in Indigenous Australians (96\% (95\% CI 82 to 100], p=0.002). Current involvement in commercial sex work (CSW) was identified by $13 \%$ (95\% CI 9 to 17) of IDUs, although many females identified sexual partnerships that facilitated drug access and supply that was not classified as CSW.

\section{Prevalence of BBVs}

Most IDUs were positive for HCV antibodies (74\% CI 69 to 79; table 4). Indigenous Australians had the highest HCV prevalence and South East Asians the lowest (94\% v 55\%, $\mathrm{p}<0.05)$. There was no difference in HCV prevalence between males and females $(76 \% \vee 71 \%$ respectively, $\mathrm{p}=0.34)$.

Serological evidence of past exposure to HAV and HBV was common; $28 \%$ (CI 23 to $33 \%$ ) had detectable HAV antibody and $33 \%$ HBV core antibody (CI 28 to 38 ). HBV carriage was uncommon ( $3 \%$ CI 1 to 5 ). Exposure to both viruses was more common in South East Asian and Indigenous Australian IDUs than in Anglo-Australians $(p=0.01$ and $\mathrm{p}<0.001$, respectively). HIV was uncommon ( $1 \%$ CI 0.2 to 3 ), occurring in three individuals of South East Asian background.

\section{Risk factors for BBVs}

HCV antibodies were more common in older individuals who had injected for a longer period $(\mathrm{p}<0.01$, table 4$)$. Cultural background did not remain a statistically significant risk factor for HCV infection by logistic regression analysis controlling for age and duration of heroin use.

Many individuals (36\% CI 30 to 43 ) were unaware of their HCV infection before testing positive for HCV antibodies. South East Asian and Indigenous Australian IDUs had the lowest levels of awareness, 58\% and 53\% respectively.

Table 3 Risk behaviours for STIs

\begin{tabular}{|c|c|c|c|c|c|c|}
\hline & All (314) & AA (223) & IA (34) & SEA (22) & Other (35) & $\mathrm{p}$ Value \\
\hline CSP in past 6 months & $130 / 273(48 \%)$ & $100 / 198(51 \%)$ & 10/31 (32\%) & $7 / 18(40 \%)$ & $13 / 26(50 \%)$ & 0.24 \\
\hline $\begin{array}{l}\text { Mean no of CSPs in past } \\
6 \text { months }\end{array}$ & $1.3(0-30)$ & $1.4(0-30)$ & $0.9(0-6)$ & $0.9(0-10)$ & $1.6(0-10)$ & \\
\hline Current RSP & $159 / 284(56 \%)$ & $116 / 205(57 \%)$ & $20 / 32(63 \%)$ & $9 / 18(50 \%)$ & $14 / 29(48 \%)$ & 0.67 \\
\hline $\begin{array}{l}\text { Always practise sex without } \\
\text { condoms }\end{array}$ & $166 / 256(65 \%)$ & $113 / 181(62 \%)$ & $25 / 26(96 \%)$ & $11 / 15(73 \%)$ & $17 / 34(50 \%)$ & 0.002 \\
\hline $\begin{array}{l}\text { Always practise sex with } \\
\text { condoms }\end{array}$ & $27 / 256(11 \%)$ & $18 / 181(10 \%)$ & $0 / 26$ & $1 / 15(7 \%)$ & $8 / 34(24 \%)$ & 0.02 \\
\hline Engage in sex work & $32 / 250(13 \%)$ & $25 / 180(14 \%)$ & $3 / 29(10 \%)$ & $0 / 12$ & $4 / 29(14 \%)$ & 0.54 \\
\hline
\end{tabular}

Where the denominator is less than the total number of individuals in each group, information on the individuals omitted has not been obtained. AA, Anglo-Australian; IA, Indigenous Australian; SEA, South East Asian; Other, predominantly Middle Eastern and European. CSP, casual sexual partner; RSP, regular sexual partner. 
Table 4 BBV prevalence and risk factors among IDUs

\begin{tabular}{|c|c|c|c|c|c|c|}
\hline & All (314) & AA (223) & IA (34) & SEA (22) & Other (35) & p Value \\
\hline Mean age (years) & 26 & 26 & 28 & 22 & 24 & 0.001 \\
\hline $\mathrm{HCV}$ antibody & $232 / 314(74 \%)$ & $163 / 223(73 \%)$ & $32 / 34(94 \%)$ & $12 / 22(55 \%)$ & $25 / 35(71 \%)$ & 0.009 \\
\hline Anti-HBc & $102 / 311(33 \%)$ & $60 / 221(27 \%)$ & $15 / 34(44 \%)$ & $11 / 22(50 \%)$ & $16 / 34(47 \%)$ & 0.01 \\
\hline $\mathrm{HBV} \mathrm{s} \mathrm{Ag}$ & $9 / 311(3 \%)$ & $1 / 198(1 \%)$ & $2 / 30(7 \%)$ & $3 / 22(14 \%)$ & $3 / 34(9 \%)$ & $<0.001$ \\
\hline Anti-HBs & $163 / 288(57 \%)$ & $102 / 199(51 \%)$ & $15 / 34(44 \%)$ & $11 / 22(50 \%)$ & $24 / 35(69 \%)$ & 0.19 \\
\hline HAV antibody & $87 / 307(28.3 \%)$ & $44 / 217(20 \%)$ & $20 / 33(61 \%)$ & $14 / 22(64 \%)$ & $9 / 35(26 \%)$ & $<0.001$ \\
\hline HIV antibody & $3 / 309(1 \%)$ & $0 / 219$ & $0 / 34$ & $3 / 21(14 \%)$ & $0 / 35$ & $<0.001$ \\
\hline $\begin{array}{l}\text { Median duration of heroin } \\
\text { use (years) }\end{array}$ & 4 & 4 & 5 & 4 & 3 & 0.14 \\
\hline $\begin{array}{l}\text { Shared drug IE in past } \\
6 \text { months }\end{array}$ & $158 / 286(55 \%)$ & $100 / 204(49 \%)$ & $28 / 32(88 \%)$ & $10 / 19(53 \%)$ & $20 / 31(65 \%)$ & $<0.001$ \\
\hline Ever shared drug IE & $235 / 284(83 \%)$ & $178 / 202(88 \%)$ & $31 / 32(97 \%)$ & $13 / 19(68 \%)$ & $26 / 31(84 \%)$ & 0.03 \\
\hline Never tested for BBVs & $35 / 307(11 \%)$ & $18 / 216(8 \%)$ & $5 / 34(15 \%)$ & $7 / 20(35 \%)$ & $20 / 35(57 \%)$ & $<0.001$ \\
\hline $\begin{array}{l}\text { Pretest unaware of HCV } \\
\text { infection* }\end{array}$ & $84 / 232(36 \%)$ & $51 / 163(31 \%)$ & $17 / 32(53 \%)$ & $7 / 12(58 \%)$ & $9 / 25(36 \%)$ & 0.04 \\
\hline HBV susceptible & $111 / 288(39 \%)$ & $89 / 199(45 \%)$ & $9 / 32(28 \%)$ & $3 / 22(14 \%)$ & $10 / 34(30 \%)$ & 0.009 \\
\hline HCV $p<25$ year old & $112 / 171(66 \%)$ & & & & & $<0.001$ \\
\hline HCV $p \geqslant 25$ year old & $120 / 143$ (84\%) & & & & & \\
\hline $\begin{array}{l}\text { HCV } P \text { in IDUs injecting } \\
<3 \text { years }\end{array}$ & $50 / 98(51 \%)$ & & & & & $<0.001$ \\
\hline $\begin{array}{l}\mathrm{HCV} P \text { in IDUs injecting } \\
\geqslant 3 \text { years }\end{array}$ & $182 / 216(84 \%)$ & & & & & \\
\hline $\begin{array}{l}\text { History of blood transfusion } \\
\text { Body piercing }\end{array}$ & $\begin{array}{l}18 / 314(6 \%) \\
201 / 300(67 \%)\end{array}$ & & & & & \\
\hline Tattoos & $188 / 299(63 \%)$ & & & & & \\
\hline \multicolumn{7}{|c|}{$\begin{array}{l}\text { Where the denominator is less than the total number of individuals in each group, individuals omitted have not been tested. } \\
\mathrm{AA} \text {, Anglo-Australian; IA, Indigenous Australian; SEA, South East Asian; Other= predominantly Middle Eastern and European. } \\
\mathrm{HCV} \text {, hepatitis } \mathrm{C} ; \mathrm{HBV} \text {, hepatitis } \mathrm{B} \text {; anti-HBs }=\mathrm{HBV} \text { surface antibody, anti-HBc=HBV core antibody, sAg, surface antigen; HAV, hepatitis } \mathrm{A} ; \mathrm{P} \text {, positive; IE } \\
\text { injecting equipment. } \\
\text { * } \text { *ack of pretest awareness of } \mathrm{HCV} \text { infection is presented for those who were } \mathrm{HCV} \text { antibody positive on testing. }\end{array}$} \\
\hline
\end{tabular}

Non-Anglo-Australian IDUs were less likely to have been previously tested for BBVs $(\mathrm{p}<0.001)$. A history of shared injecting equipment (needles, spoons, or filters) in the previous 6 months was common (55\% CI 49 to 61 ), and recent sharing was most prevalent among Indigenous Australians ( $88 \%$ (CI 71 to 96 ), $\mathrm{p}<0.001$ ).

A significant proportion of IDUs was susceptible to HBV ( $39 \%$ CI 33 to 44 ), and HAV ( $72 \%$ CI 66 to 77 ). Yet few IDUs had received HBV vaccination, and had serological evidence of immunity (26\% CI 21 to 31 ). The requirement for HBV and HAV vaccination was greatest in Anglo-Australian IDUs $(\mathrm{p}<0.001)$.

\section{DISCUSSION}

In this study the use of street outreach and the introduction of self collected sampling greatly improved participation rates and acceptance of screening for STIs in IDUs. Considerable barriers to STI screening exist for this group. They often attend services with urgent health needs; preventative health care is not perceived as a priority, and genital examination is considered embarrassing and unnecessary in the absence of symptoms. Self collected sampling was much more acceptable than practitioner collected sampling in this population, and with PCR detection methods, is both sensitive and specific for the diagnosis of CT, NG, and TV. ${ }^{24}$ Self collection of genital samples appears to be ideally suited to improve STI screening rates in IDUs.

The prevalence of STIs in this study was moderate $(8 \%)$, and the prevalence of asymptomatic chlamydia (6\%) was sufficiently high to justify screening. There have been no community based estimates of chlamydia prevalence in Australia, but recent studies conducted in high risk groups in Melbourne found a chlamydia prevalence of $4 \%$ in homeless youth, ${ }^{25}$ and a prevalence of $4.8 \%$ in young females attending an adolescent family planning service. ${ }^{26}$ In keeping with studies in the United States and Europe, ${ }^{1-4}$ sexual risk taking among IDUs was common, with high rates of unprotected sex and casual sexual partners. The high risk sexual behaviours and moderate STI prevalence found in IDUs in this study highlights the need for more widespread and acceptable STI screening practices in this group.

Australia has adopted a harm reduction approach to injecting drug use since the 1980s. ${ }^{11}$ Despite widespread needle syringe exchange and drug replacement programmes, and targeted education regarding safe injecting and sexual practices, the incidence and prevalence of HCV remains high. ${ }^{6}{ }^{10}{ }^{12}$ While the low prevalence of HIV in Australian IDUs is credited in part to the success of these strategies, there appears to have been no significant impact on HCV transmission. ${ }^{16}$ We identified a high prevalence of HCV infection and recent sharing of injecting equipment in IDUs in Melbourne. This HCV prevalence is at the higher end of prevalence studies conducted in IDUs in Australia. ${ }^{6}{ }^{10} 1216 \mathrm{It}$ is of considerable concern that a significant proportion of HCV infected IDUs in this study were unaware of their infection, particularly IDUs from a non-Anglo-Australian background, who reported lower rates of previous testing. Many IDUs expressed concern about health professionals damaging their veins when testing for BBVs. Permitting individuals to collect their own blood sample if they preferred enabled us to achieve a high rate of BBV screening.

A significant proportion of IDUs were susceptible to either HBV or HAV infection, and had not received vaccination. It appears current HBV vaccine initiatives are not adequate. Despite guidelines recommending universal vaccination, hepatitis B vaccine coverage has been reported to be low in most risk groups in high income countries. ${ }^{27}$

The HIV prevalence in this study was relatively low (1\%), in keeping with the prevalence reported in IDUs in other Australian studies. ${ }^{12} 16$ However, the high prevalence of unsafe sexual and injecting practices places IDUs at substantial risk of HIV transmission. There has been a recent increase in HIV notifications in IDUs of South East Asian origin in Victoria, Australia. ${ }^{28}$ Recent studies indicate that unsafe injecting practices in this group are common ${ }^{29}$ and that they are under-represented in treatment programmes. ${ }^{30}$ 


\section{Key messages}

- Injecting drug users (IDUs) are a marginalised population, who infrequently access health services for screening for STls and blood borne viruses (BBVs), and are at high risk of these infections

- Street outreach and self directed STI screening were acceptable to IDUs, achieved high rates of participation, and a high prevalence of BBVs, STIs and risk behaviours was identified using these methods

- We propose that sexual health services for IDUs should include street outreach programmes, and adopt acceptable methods to facilitate STI and BBV screening

- Novel approaches that actively seek to improve access and acceptability of health services for IDUs, are more likely to be utilised, and to prove effective in achieving a sustained impact on behaviour and disease transmission

Movement between Australia and cities in SouthEast Asia where the HIV prevalence in IDUs may exceed $50 \%$ and safe injecting equipment is not readily available, is being increasingly reported.$^{28}$ The three cases of HIV identified in our study occurred in South East Asian IDUs, who had briefly returned to their country of birth where they had injected. There is an urgent need for drug services that access, educate, and meet the needs of individuals from culturally diverse backgrounds.

There were several considerations in interpreting results from this study. It was not possible to obtain accurate data on those who were aware of the service, but did not choose to participate in the study. Anecdotally those who declined to attend gave reasons such as being "too busy," or having "just been tested." It is possible that the non-attenders may have been at different risk than those who accepted screening. Data on sexual risk practice were obtained for $80 \%$ of participants. Missing data may have led to an underestimate risk practices, as IDUs who declined to fully complete the questionnaires and interviews often had other urgent needs that took priority. In $24 \%$ of IDUs self directed STI screening was declined or not possible. This group was more likely to be male, and most did not decline but were unable to void after recent heroin use. This difficulty was seen only in men. Those who were not screened were not more likely to have engaged in unprotected sex, had fewer sexual partners, and were less likely to engage in sex work. It is unlikely that they were more at risk of STIs, but absence of testing of these individuals may have altered STI prevalence in the overall group.

The high HCV prevalence in this study may reflect the nature of this outreach service. The programme targeted street based IDUs, who tended to be a population of chronic drug users who infrequently accessed health services. Thus the risk behaviours and disease prevalence found in this study may not be applicable to all IDU groups. The cross sectional study design enabled us only to derive disease prevalence, and we are not able to comment on the incidence of BBVs or STIs over this period.

Injecting drug users are a high risk group for both BBVs and STIs; however, significant economic, geographical, and societal factors create barriers to the access of health services for this group. Street outreach and self directed STI screening were acceptable to IDUs in this programme. Introduction of these novel methods improved access to this marginalised group who are rarely screened for STIs, and achieved high rates of participation. A high prevalence of infections and risk behaviours was identified using these methods. We propose that sexual health services for IDUs should include street outreach programmes, and adopt acceptable methods to facilitate STI and BBV screening. Programmes that take into consideration the culturally diverse nature of urban IDUs, and that actively seek to improve access and acceptability of health services for this heterogeneous group, are more likely to be utilised, and to prove effective in achieving a sustained impact on behaviour and disease transmission.

\section{ACKNOWLEDGEMENTS}

We wish to thank the staff of Collins Street Baptist Church, The Footpatrol, Open Family and The Action Centre, and the nursing, medical, and laboratory staff at Melbourne Sexual Health Centre, for their involvement and support of the project. Lastly, thanks to James Beeson for his extensive review of the manuscript.

\section{CONTRIBUTORS}

CSB, principal author, study coordination, study design, data collection, data analysis; LIP, study design, study coordination, and data collection; SNT, molecular biology, laboratory data, and contributing author; CKF, data analysis and contributing author; SMG, study design, laboratory data, and contributing author; all authors listed have made a significant contribution to this work.

\section{Authors' affiliations}

C S Bradshaw, LI Pierce, C K Fairley, Melbourne Sexual Health Centre, The Alfred Hospital, Victoria, Australia

C S Bradshaw, C K Fairley, School of Population Health, University of Melbourne, Victoria, Australia

S N Tabrizi, S M Garland, Department of Microbiology and Infectious Diseases, The Royal Women's Hospital, Victoria, Australia

Conflict of interest: none declared.

\section{REFERENCES}

1 Ross MW, Gold J, Wodak A, et al. Sexually transmissible diseases in injecting drug users. Genitourin Med 1991;67:32-6.

2 Ross MW, Hwang LY, Zack C, et al. Sexual risk behaviours and STIs in drug abuse treatment populations whose drug of choice is crack cocaine. Int J STD AIDS 2002;13:769-74.

3 Poulin C, Alary M, Bernier F, et al. Prevalence of Chlamydia trachomatis and Neisseria gonorrhoeae among at-risk women, young sex workers, and street youth attending community organizations in Quebec City, Canada. Sex Transm Dis 2001;28:437-43.

4 Van den Hoek A. STD control in drug users and street youth. Genitourin Med 1997;73:240-4.

5 Miller M, Mella I, Moi $\mathrm{H}$, et al. HIV and hepatitis $\mathrm{C}$ virus risk in new and longer-term injecting drug users in Oslo, Norway. J Acquir Immune Defic Syndr 2003;33:373-9.

6 MacDonald MA, Wodak AD, Dolan KA, et al. Hepatitis C virus antibody prevalence among injecting drug users at selected needle and syringe programs in Australia, 1995-1997. Collaboration of Australian NSPs. Med J Aust 2000;172:57-61.

7 Van Beek I, Buckley R, Stewart M, et al. Risk factors for hepatitis C virus infection among injecting drug users in Sydney. Genitourin Med 1994;70:321-4.

8 Freeman AJ, Zekry A, Whybin LR, et al. Hepatitis C prevalence among Australian injecting drug users in the 1970s and profiles of virus genotypes in the 1970s and 1990s. Med J Aust 2000;172:588-91.

9 Des Jarlais DC, Diaz T, Perlis T, et al. Variability in the incidence of human immunodeficiency virus, hepatitis $B$ virus, and hepatitis $C$ virus infection among young injecting drug users in New York City. Am J Epidemiol 2003;157:467-71.

10 Crofts N, Hopper J, Bowden S. Hepatitis C virus infection among a cohort of Victorian injecting drug users. Med J Aust 1993;159:237-41.

11 Law MG, Batey RG. Injecting drug use in Australia: needle/syringe exchange programs prove their worth, but hepatitis $C$ still on the increase. Med J Aust 2003;178:197-8.

12 Crofts N, Aitken CK. Incidence of bloodborne virus infection and risk behaviours in a cohort of injecting drug users in Victoria, 1990-1995. Med J Aust 1997; 167:17-20.

13 Crofts N, Cooper G, Stewart T, et al. Exposure to hepatitis A virus among blood donors, injecting drug users and prison entrants in Victoria. J Viral Hepat 1997;4:333-8.

14 Rhodes T, Lowndes C, Judd A, et al. Explosive spread and high prevalence of HIV infection among injecting drug users in Togliatti City, Russia. AIDS 2002; 16:F25-31.

15 Shafer KP, Hahn JA, Lum PJ, et al. Prevalence and correlates of HIV infection among young injection drug users in San Francisco. J Acquir Immune Defic Syndr 2002;31:422-31. 
16 Van Beek I, Dwyer R, Dore GJ, et al. Infection with HIV and hepatitis C virus among injecting drug users in a prevention setting: retrospective cohort study. BMJ 1998;317:433-7.

17 Tabrizi SN, Paterson B, Fairley CK, et al. A self-administered technique for the detection of sexually transmitted diseases in remote communities. J Infect Dis 1997; 176:289-92.

18 Tabrizi SN, Chen S, Borg AJ, et al. Patient-administered tampon-collected genital cells in the assessment of Chlamydia trachomatis infection using polymerase chain reaction. Sex Transm Dis 1996;23:494-7.

19 Miller CL, Tyndall M, Spittal P, et al. Risk-taking behaviors among injecting drug users who obtain syringes from pharmacies, fixed sites, and mobile van needle exchanges. J Urban Health 2002;79:257-65.

20 Knox J, Tabrizi SN, Miller P, et al. Evaluation of self-collected samples in contrast to practitioner-collected samples for detection of Chlamydia trachomatis, Neisseria gonorrhoeae, and Trichomonas vaginalis by polymerase chain reaction among women living in remote areas. Sex Transm Dis 2002;29:647-54.

21 Paterson BA, Tabrizi SN, Garland SM, et al. The tampon test for trichomoniasis: a comparison between conventional methods and a polymerase chain reaction for Trichomonas vaginalis in women. Sex Transm Infect 1998;74:136-9.

22 Resnick RM, Cornelissen MT, Wright DK, et al. Detection and typing of human papillomavirus in archival cervical cancer specimens by DNA amplification with consensus primers. J Natl Cancer Inst 1990;82:1477-84.
23 Tabrizi SN CS, Cohenford MA, Lentrichia BB et al. Evaluation of real-time polymerase chain reaction assays for confirmation of Neisseria gonorrhoeae in clinical samples tested positive in the Roche Cobas Amplicor assay. Sex Transm Dis 2004:80:68-71.

24 Tabrizi SN, Paterson BA, Fairley CK, et al. Comparison of tampon and urine as self-administered methods of specimen collection in the detection of Chlamydia trachomatis, Neisseria gonorrhoeae and Trichomonas vaginalis in women. Int J STD AIDS 1998;9:347-9.

25 Rosenthal DA, Fairley CK, Garland SM, et al. Homeless young people: an important risk group for sexually transmitted infections. Med J Aust $2000 ; 172: 244$

26 Williams H, Tabrizi SN, Lee W, et al. Adolescence and other risk factors for Chlamydia trachomatis genitourinary infection in women in Melbourne, Australia. Sex Transm Infect 2003;79:31-4.

27 Francois G, Hallauer J, Van Damme P. Hepatitis B vaccination: how to reach risk groups. Vaccine 2002;21:1-4.

28 Hocking JS, Higgs PG, Keenan CM, et al. HIV among injecting drug users of Indo-Chinese ethnicity in Victoria. Med J Aust 2002;176:191-2.

29 Maher L, Sargent $P$, Higgs $P$, et al. Risk behaviours of young Indo-Chinese injecting drug users in Sydney and Melbourne. Aust NZ J Public Health $2001 ; 25: 50-4$.

30 Reid G, Crofts N, Beyer L. Drug treatment services for ethnic communities in Victoria, Australia: an examination of cultural and institutional barriers. Ethn Health $2001 ; 6: 13-26$.

\section{$\mathrm{ECHO}$}

\section{HIV prophylaxis after sexual assault}

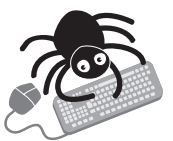

Please visit the Sexually Transmitted Infections website [www. stijournal.com] for a link to the full text of this article.
A mong healthcare workers exposed to risk of HIV infection as a result of needlestick injury post-exposure prophylaxis (PEP) with zidovudine reduced seroconversion by $80 \%$. In 1998 the New York State Department of Health issued guidelines recommending HIV PEP for all victims of sexual assault involving vaginal or anal intercourse who presented within 36 hours and whose assailant was either HIV infected or of unknown HIV status. Current practise for female adolescents presenting to a New York City paediatric emergency department after sexual assault has been reported.

A retrospective search for the two year period January 1999 to December 2000 identified 25 patients who attended the paediatric emergency department after sexual assault. Fourteen adolescent females, all of whom had suffered vaginal intercourse, had received HIV PEP. In addition, one 15 year old declined HIV PEP and two patients aged 13 and 14 were asked to attend follow up for discussion of HIV PEP.

The 14 patients who received HIV PEP ranged in aged from 12 to 19 years and 12 were 15 years or older. Nine knew their attacker but none knew his HIV status. Four had also suffered oral sex and two anal. Two of the men had used a condom. The time from assault to presentation ranged from three to 72 hours and six patients presented later than 24 hours. They received the PEP an average of 58 minutes after presentation, one with zidovudine alone and the rest with three drugs including either zidovudine and lamivudine (12) or stavudine and lamivudine (1) with either nelfinavir (9) or indinavir (4). Thirteen patients accepted prophylaxis against chlamydia and gonorrhoea and 12 took emergency contraception. There was no follow up.

The authors of this paper suggest that provision of HIV PEP in the emergency department should be expedited through education of medical staff about HIV PEP and by making the appropriate drugs available for immediate dispensing in the department.

A Emergency Medicine Journal 2004;21:449-451. 